\title{
Methotrexate-Associated Lymphoproliferative Disorder
}

National Cancer Institute

\section{Source}

National Cancer Institute. Methotrexate-Associated Lymphoproliferative Disorder. NCI

Thesaurus. Code C7184.

A lymphoproliferative disorder that develops in patients who are immunosuppressed with methotrexate. This disorder is often Epstein-Barr virus positive, and morphologically it may resemble large B-cell non-Hodgkin lymphoma, Hodgkin lymphoma, or a polymorphous post-transplant lymphoproliferative disorder. (WHO, 2001) 